\title{
The Influence of Geometrical Parameters of a Tool on its Wear in Selected Technological Processes
}

\author{
Irena Nowotyńska ${ }^{1 *}$ \\ 1 Rzeszow University of Technology, Department of Computer Engineering in Management, Al. Powstańców \\ Warszawy 8, 35-959 Rzeszów, Poland \\ *Corresponding author's email: i_nowot@prz.edu.pl
}

\begin{abstract}
Forecasting the durability of tools for various technological processes and determining the dominant destructive mechanisms or their impact on the "life time" of the tool is very important. In the paper presents the research on tools wear of different geometric parameters in selected plastic working processes were presented. The numerical calculations of the tool wear in the process of forward extrusion and drawing were carried out using the MSC MARC program, based on the Finite Element Method. In order to determine the amount of wear of dies and drawing dies, the Archard model was applied. The model was implemented in the FEM-based program. As a result of the research, the areas on the surface of tools, which are particularly exposed to significant wear were determined, depending on their geometry.
\end{abstract}

Keywords: tool, wear, extrusion, drawing.

\section{INTRODUCTION}

Durability of tools is one of the most difficult parameters to control in technological processes. Manufacturing items by means of plastic forming methods requires the use of reliable tools. Plastic working tools should ensure high quality of finished products with a sufficiently large production volume and low production costs. The most common assumption is that tool life is expressed in the number of operations that can be performed with this tool to obtain products of the required quality. Extrusion and drawing are among the manufacturing processes in which the tool geometry has a particular impact on the quality of products. The extrusion process is considered to be one of the most important metal forming processes. This is due to its high efficiency, as well as low cost. Currently, the extrusion process is considered the most widely applied manufacturing process in the production of components used mainly in aviation and other areas of mechanical production [1]. During extrusion, most metals have very high plastic deformability as a result of triaxial compression with high stress values. Any restrictions on the extrusion application are introduced due to the durability and strength of the tools. Dies are the elements most exposed to wear, which - at the same time - have the greatest impact on the dimensional accuracy and surface quality of the product. According to the research conducted by Stahlbergh and Hallstorm [2], more than $70 \%$ of die substitutes result from their wear during extrusion. Therefore, it is important to determine the influence of technological parameters, including geometric dies, on their wear, and thus help extend their service life. In order to investigate and predict the behavior of the tool during the extrusion of various materials, both numerical and experimental studies were carried out $[3 \div 13]$. In order to obtain the information on the influence of metal flow, temperature, strain and stress on the die durability, Altan and Knoerr [3] performed a finite element analysis using the commercial program DEFORM. It turned out that the stress concentration in the dies was directly related to their service life and it was found that by 
inducing stress relief through the changes in the die geometry, the die service life could be improved. [4] describes a simulation wear test of forming tools, which was developed to evaluate the comparative performance of a series of established and newly developed hot work dies. On the other hand, in [5] the wear profiles and local stress concentrations for two cold extrusion processes were investigated. Kang et al. $[6,7]$ proposed a new wear model considering thermal softening and used it to calculate the wear of the profile of a rotor pole for automobile produced in the hot forging process. In [8], the author analyzed the nature of friction and wear, as well as some theoretical relationships linking the characteristics of processes and properties of bodies in contact, necessary for the practical application of the theory to calculate friction forces and wear values. The work [9] concerns the study of wear in the metal forming process. In turn, the purpose of the work [10] was a statistical analysis of the control of the tool wear evolution process during the metal extrusion process in order to better understand the main reasons generating the variability of such a complex phenomenon. The study was based on the application of central composite designs and allowed the analysis of the sensitivity (to wear) of the tool. Painter et al. [11] analyzed the die wear during hot extrusion using the finite element method by means of the DEFORM program and the WEAR program for predicting the wear conditions. In the work [12], selected technological problems occurring during the process of extrusion of elements were discussed; in particular, the wear of tools was discussed. The evaluation of the process was performed on the basis of the maps of the deformation intensity distribution and the tool wear index, determined using the QForm3D program and based on the determined equation of the expected tool life. Sobis et al. [13] studied the actual contact areas for predicting wear, which is within the limits specified in the Archard model. For instance, Hild et al. [14] focused on the substitution of lubricants during forward extrusion by surface textures on workpieces and self-lubricating coatings on tools. The tool wear during the extrusion of aluminum alloys was also investigated [15, 16]. Zhang investigated the die wear behavior during the extrusion of 7075 aluminum alloy tubes. In his study, based on a modified Archards wear mod$\mathrm{el}$, the numerical results were generated by means of Deform-3D showing the process variables that have multiple effects on the die behavior [15]. Bjork investigated the effect of wear on surface treated dies for aluminum extrusion by coating the surface by physical gaseous phase deposition [16].

Drawing, like the extrusion process, belongs to the processes of plastic processing of metals. The drawing process consists in reducing the cross section of the material in a tool called a drawing die. The shape of the crushing zone for a monolithic die, depending on its purpose, can be conical, curved, concave and sigmoidal.

As a result of the using of dies in the working part of the tools, the wear elements are in the form of matting of the surface, drawing rings, scratches and cracks. There are three wear zones. The first wear zone is located in the area of the entry plane. The second one is the pulling cone and the third is at the die exit. The wear processes of dies were the subject of many studies $[17 \div 22]$. Kim et al. [21] used the Archard's wear model for a wiredrawing process to calculate the die-wear depth by considering the hardness of the die as a function of the die temperature. On the other hand, in [23] an advanced simulation was proposed which took into account the influence of wire vibrations to accurately predict the wear profiles of the die used in the wire drawing process. This simulation investigated the effects of wire vibration, changes in wear profiles and ring formation when approaching the die. In [24] the authors suggested that a mechanical approach was insufficient to explain the wear phenomena observed during wet wire drawing. In addition, precision wire products are affected by the heat generated in the contact zone [25]. Deng et al. [26] performed wire-drawing tests with a ceramic composite die and $65-\mathrm{Mn}$ steel wire. The results of these tests indicated that the most common reason for the failure of the ceramic drawing die was the wear in the approach zone owing to high compressive stress. The subject of wear was also discussed in the works $[27 \div 28]$.

The durability of tools in the mentioned processes is associated with the occurrence of various destructive phenomena. Abrasive wear is the most common type of wear in plastic forming processes caused by the friction between the working surface of the tool and the extruded or drawn material. The research on the die wear mechanisms resulted in the proposition of mathematical models that takes into account the parameters influencing the wear process. The earliest attempt to link wear with the mechanical properties of materials was made by Tonn [8], who determined the empirical equation of abrasive wear. Then Archard [29] developed the adhesive wear theory and proposed an 
adhesive wear model based on the work of Holm [30]. This model assumes that the amount of wear is a function of normal load and frictional path. Moreover, a lot of work, for example [13, 23] was devoted to the use of this wear model to study the wear characteristics of dies during metal forming.

Forecasting the durability of the tools for plastic working and determining the dominant destructive mechanisms, or their impact on the "life" of the tool are very important and still not fully resolved problems. Development of the methods that allow determining the wear (damage) of tools and forecast their durability is justified, among others, by reducing the costs associated with the manufacturing of the tools themselves, the unit costs of the product, as well as environmental aspects [31]. Modern information technologies are constantly providing new methods and tools that make it possible to partially replace expensive and time-consuming material experiments with a virtual experiment. They allow one to optimize the die design process by effectively predicting die wear and fatigue.

As shown in the introduction, many research works are carried out in order to improve the operating conditions and increase the durability of plastic working tools. A large part of the work concerns the influence of various processed materials and technological parameters on the durability of tools. There are also studies on the influence of various coatings on tool life. A large amount of research work proves that the problem is still difficult to solve.

The study on the influence of the geometric parameters of the tool on its durability in the technological process is particularly important from the point of view of their durability and quality of the product manufactured. There may be times when the tool geometry becomes the main factor in the changeability. The research carried out in the work may not only facilitate the outlining of activities aimed at reducing the intensity of tool wear and extending their service life by, for example, modifying their geometry, but also indicate the need to introduce corrections to the models used to describe tool wear.

The aim of the paper is to determine the influence of geometric parameters of a tool on its durability in the process of extrusion and drawing by means of the Archard model. The analysis of the research results carried out in the paper may facilitate the outlining of activities aimed at reducing the intensity of tool wear and extending the time of their operation by, for instance, modifying their geometry.

\section{NUMERICAL MODELING}

The adhesive wear of the tool in both processes was determined from the relationship proposed by Archard [29]:

$$
d V=k \frac{d F d L}{H}
$$

where: $k$ - wear coefficient, $d V$ - volumetric consumption, $d F-$ normal force, $d L-$ friction path, $H$ - hardness.

In the research, the wear profile of the dies was calculated by implementing the Archard wear model into the MARC program in the form of:

$$
\stackrel{o}{w}=\frac{k}{H} \sigma_{n} v_{r e l}
$$

where: $\stackrel{o}{w}$ - wear speed, $\sigma_{n}$ - normal stress on contact, $v_{\text {rel }}$ - relative sliding speed

The amount of wear determined by the depth of wear in the extrusion process was calculated from the dependence:

$$
w_{n+1}=w_{n}+\stackrel{o}{w \Delta t}
$$

where: $w_{n+1}$ - current value of the depth of wear, $w_{n}-$ consumption value in the previous calculation step, $w$ - wear speed, $\Delta t-$ time in the calculation step

For the analysis of the influence of the die angle on the wear rate in the tests of the extrusion process, the value of the $k$ coefficient was assumed to be $10^{-4}$ [5]. In order to estimate the quantitative consumption for the modeled cases in the drawing process, the relationship (2) was modified to the form:

$$
\stackrel{o}{w}=\frac{k}{H} \frac{m}{m_{F E M}} \sigma v_{r e l}
$$

where: $m$ - actual mass of the wire drawn through the die, $m_{F E M}$ - wire mass drawn through the die during FEM modeling.

In the tests of the drawing process, the values of individual quantities were adopted based on the literature data [32]: $k=3 \cdot 10^{-10}, H=17,000$ $\mathrm{MPa}, m=6.35 \mathrm{Mg}, m_{F E M}=4.45 \cdot 10^{-6} \mathrm{Mg}$.

\section{Extrusion process}

Numerical modeling of the extrusion process was carried out with the use of the MARC/Mentat program by MSC Software. Numerical modeling of the extrusion process was carried out for two geometric variants: a flat die $\left(\alpha=90^{\circ}\right)$ and for three die hole diameter, $D_{O}==(20.78 \mathrm{~mm} ; 13.61$ $\mathrm{mm} ; 10.85 \mathrm{~mm})$ as well as for a flat die $\left(\alpha=90^{\circ}\right)$ and convex dies with working cone angles $\alpha=$ 


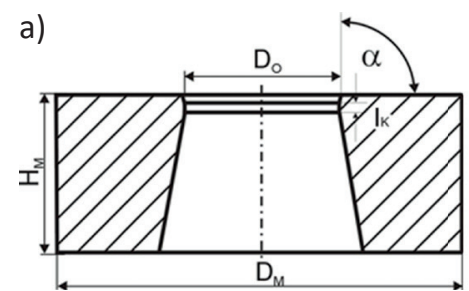

b)

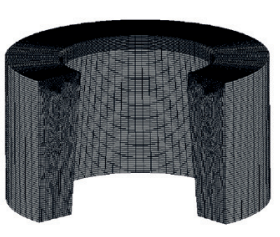

Fig. 1. Tool diagram - a) and its geometry with finite element mesh $-\mathrm{b}), \alpha=90^{\circ}, 95^{\circ}, 105^{\circ}$,

$D_{M}=36 \mathrm{~mm}, H_{M}=20 \mathrm{~mm}, l_{k}=2 \mathrm{~mm}$, $D_{O}=(20.78 \mathrm{~mm} ; 13.61 \mathrm{~mm} ; 10.85 \mathrm{~mm})$

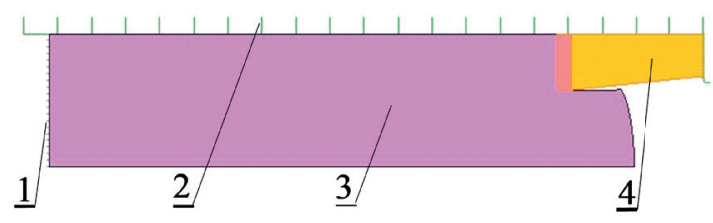

Fig. 2. Axisymmetric geometrical model of the FEM simulation of extrusion process: 1 - punch, 2 - container, 3 - billet, 4 - die

$95^{\circ}$ and $\alpha=105^{\circ}$ and $D_{O}=20.78 \mathrm{~mm}$ (Fig. 1). The adopted model is a two-dimensional model that was analyzed assuming an axisymmetric stress condition. An exemplary geometry of the model made with a mesh of deformable body elements is shown in in Figure 2.

It was assumed that the surfaces of the punch and the container were perfectly rigid. The mechanical properties of the deformable die were described assuming $E=210000 \mathrm{MPa}$ and $v=0.3$. On the other hand, the properties of the extruded material were described by adopting a model of a rigidly plastic body with nonlinear hardening. The course of the strengthening curve for the extruded material was described by the Hollomon equation in the form:

$$
\sigma_{p l}=K \varphi_{i}^{n}
$$

The extruded material was lead of the OT3 grade. The values of the material constants for hard lead were $K=40 \mathrm{MPa}, n=0.23$. The friction model was described by Coulomb's law. The friction coefficients between the extruded material and the tools and the container were assumed as $\mu=0.25$, and between the deformable die and the container - as $\mu=0.1$. In order to create FEM grid of extrusion material Class 4 Type 10 elements were used - is a four-node, isoparametric, arbitrary quadrilateral written for axisymmetric applications. In order to create FEM grid of deformable die Class 3 Type 2 elements were used - three-node, isoparametric, triangular element. It is written for axisymmetric applications and uses bilinear interpolation functions [33].

\section{The drawing process}

Numerical modeling of the drawing process was also carried out using the MARC/Mentat software. The shape and geometrical dimensions of the tools used during modeling are shown in the Figure 3.

A copper wire with an initial diameter of 3.6 $\mathrm{mm}$ was pulled through the die nib with a diameter of $3 \mathrm{~mm}$. Hence, the value of the draft was equal to about $30 \%$ of the relative loss of the cross-section. The drawing die was made of cemented carbide. Its properties were described
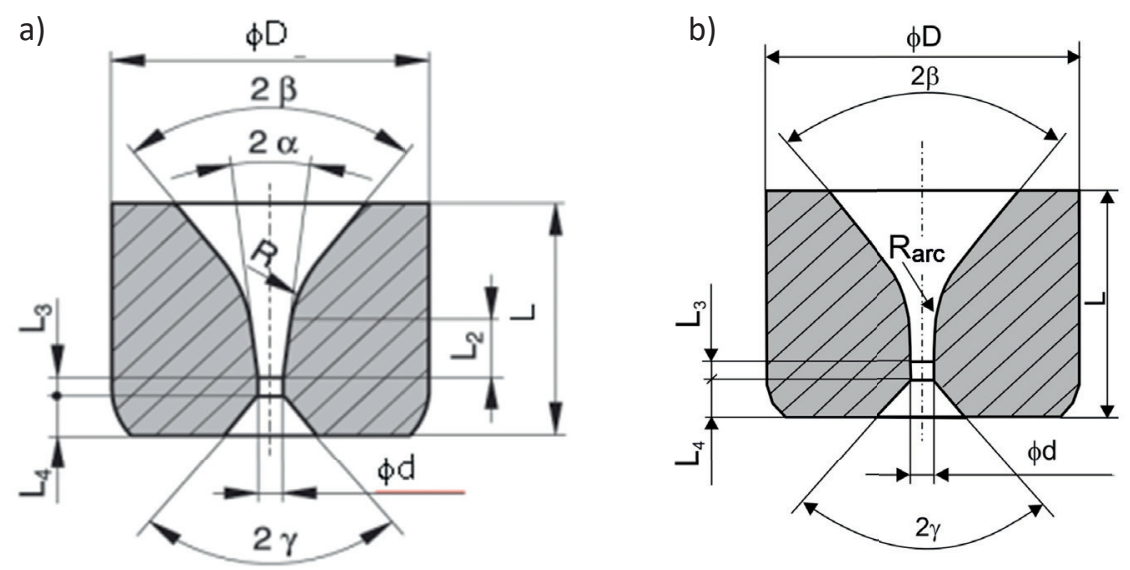

Fig. 3. Dimensions of test tools: a) conical drawing die, b) arc die - $\phi d=3 \mathrm{~mm}, \phi D=20.45 \mathrm{~mm}, R=10 \mathrm{~mm}$, $2 \beta=2 \gamma=60^{\circ}, 2 \alpha=18^{\circ}, L=17 \mathrm{~mm}, L_{2}=5.2 \mathrm{~mm}, L_{3}=1.5 \mathrm{~mm}, L_{4}=3.2 \mathrm{~mm}, R_{a r c}=14.5 \mathrm{~mm}$ 
with the assumption of an ideally elastic material model, assuming $E=620000 \mathrm{MPa}$ and $v=0.22$ [34]. Copper wire (M1E) was a deformable material. In order to describe its properties, an elasticplastic material model with a nonlinear hardening was used. The stress-strain relationship in the range of plastic strains is described by the Hollomon power equation. The mechanical parameters of the wire material used for modeling were as follows: $E=127000 \mathrm{MPa}, v=0.35, R_{e}=57$ $\mathrm{MPa}, R_{m}=227 \mathrm{MPa}, K=368 \mathrm{MPa}$ and $n=0.3$. The friction between deformable materials was described by the Coulomb model. The coefficient of friction between the drawn bar and the drawing die was to be equal to $\mu=0.07$ [34]. It was also assumed that the trench drawing speed was constant $v=0.7 \mathrm{~m} / \mathrm{s}$. The tool model in the case of the drawing process had two meshes of elements connected to each other by the glue contact condition. The average mesh size in the compacted area was $0.05 \mathrm{~mm}$, while the non-compacted area was approximately $0.35 \mathrm{~mm}$. The initial size of the drawn wire mesh was $0.05 \mathrm{~mm}$. In total, the numerical model consisted of approximately 24 000 finite elements [33].

\section{VALIDATION OF NUMERICAL MODELS}

In order to determine the correctness of the numerical tests concerning the extrusion process, experimental tests were carried out on a vertical press equipped with a system that enables the registration of the extrusion force and the displacement of the stamp (Fig. 4). A flat die made of NC10 steel was selected for the experimental tests. The values of the geometric parameters of the die used for the experimental tests were the same as in the modeling. The chemical composition of the extruded material (OT3) used in the tests is presented in Table 1 [35]. However, the yield stress $R_{e}\left(R_{e}=10 \mathrm{MPa}\right)$ and Brinell hardness $(\mathrm{HB}=8.7)$ were determined experimentally. In Table 1, the data on the chemical composition were taken from the literature, while the yield strength Re and Brinell hardness were determined experimentally by the author.

After the conducted experimental tests, the force characteristics were prepared and then compared with those obtained in the simulations. Figure 5 shows the course of the extrusion force change depending on the displacement of the punch obtained in the experimental way and in
Table 1. Chemical composition of material used in investigations

\begin{tabular}{|c|c|}
\hline Material & Chemical composition [\%] \\
\hline $\begin{array}{c}\text { Hard lead } \\
\text { OT3 }\end{array}$ & $2.5-3.5 \mathrm{Sb} ; 0.01 \mathrm{As} ; 0.02 \mathrm{Cu} ;$ \\
$0.005 \mathrm{Fe} ; 0.04 \mathrm{Bi}$ \\
\hline
\end{tabular}

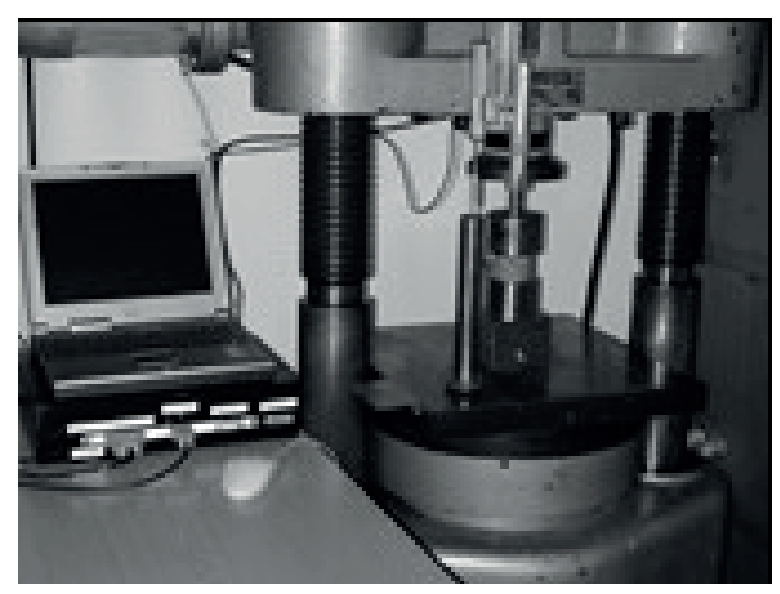

Fig. 4. Scheme of a test setup for extrusion

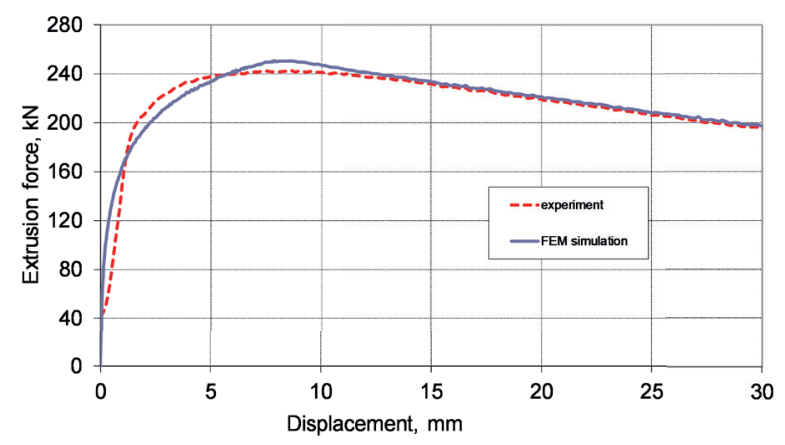

Fig. 5. Experimental and numerical force characteristic of extrusion process

the numerical simulation. The large convergence of both waveforms proves the correctness of the parameters adopted in the numerical simulation.

On the other hand, the validation of the numerical model concerning the drawing process was carried out by comparing the average value of the drawing force obtained in the numerical simulation with the value of the force, which was calculated from the formula for the drawing force contained in [36]. The authors conducted experimental tests, obtained the values of the drawing force for various angles, and compared them with the values of the forces calculated on the basis of the mathematical formula. They noted that the average value of the difference 


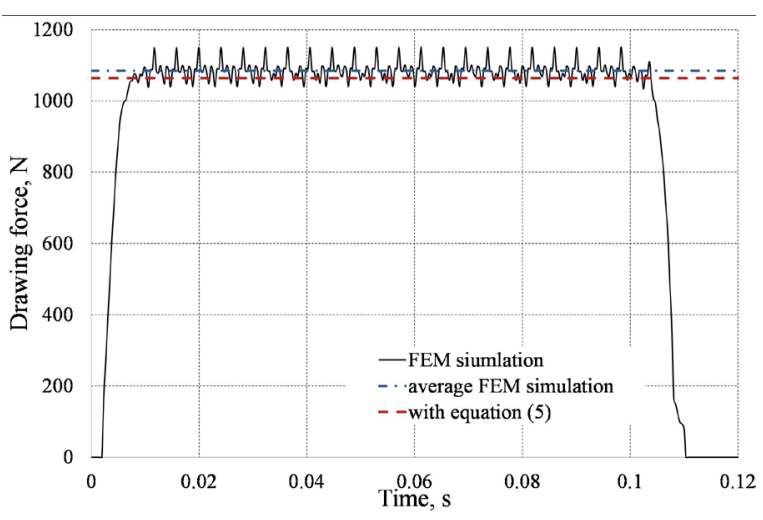

Fig. 6. Drawing force diagram

between the force calculated from the dependence and the experimental force was about $2.5 \%$. Hence, for the case under consideration, the average value of the drawing force calculated by FEM was $1085 \mathrm{~N}$, while the value of the drawing force calculated using the formula was $1064 \mathrm{~N}$. Therefore, the force calculated in the numerical simulation is only $2 \%$ higher than the force calculated from the mathematical dependence, which proves the correctness of the applied FEM model for analyzing the drawing process. The course of the drawing force calculated in the FEM simulation is shown in Figure 6.

\section{RESULTS AND THEIR ANALYSIS}

In order to determine the influence of the die geometry on the tool wear, 22 measuring points were selected for each of the tested dies in extrusion process (Fig. 7).

In order to determine the depth of wear caused by the movement of the material on the surface of the die, the relationship (3) was used. After analyzing the results from numerical modeling, it was found that the highest wear values occurred in the area of the tool radius (Fig. 8). Such a location of wear may have negative consequences in the form of failure to meet the predetermined dimensions and deterioration of the quality of the surface of the extruded product.

Figure 9 shows the maximum calculated values of the depth of wear for individual dies in critical areas. The highest value was recorded for a convex die with an angle $\alpha=95^{\circ}$ and the smallest for a convex die with an angle $\alpha=105^{\circ}$. Figure 10 shows the increase in the depth of wear at individual measuring points depending on the displacement of the punch for selected dies.

The determined wear depths for the tool geometries are shown in Figure 11. The visible results indicate that the greatest local wear of the die took place when the working cone angle was $95^{\circ}$ and amounted to $0.0007 \mathrm{~mm}$. The calculation results indicate that the die geometry in this case expressed by the angle of the working cone has a significant impact on the amount of the tool wear. The area at the entrance to the die opening

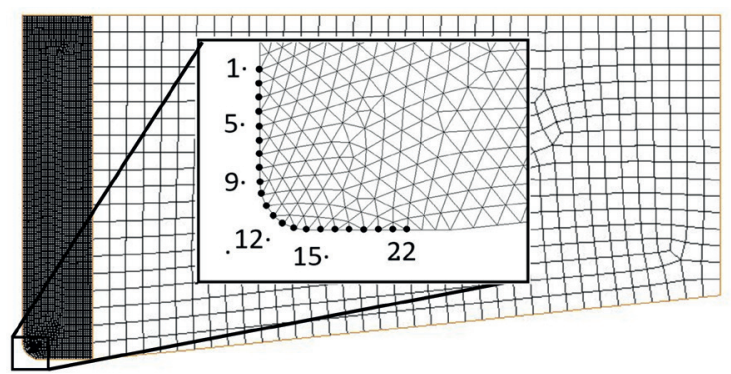

Fig. 7. Locations of measurement points of depth consumption in the tested dies

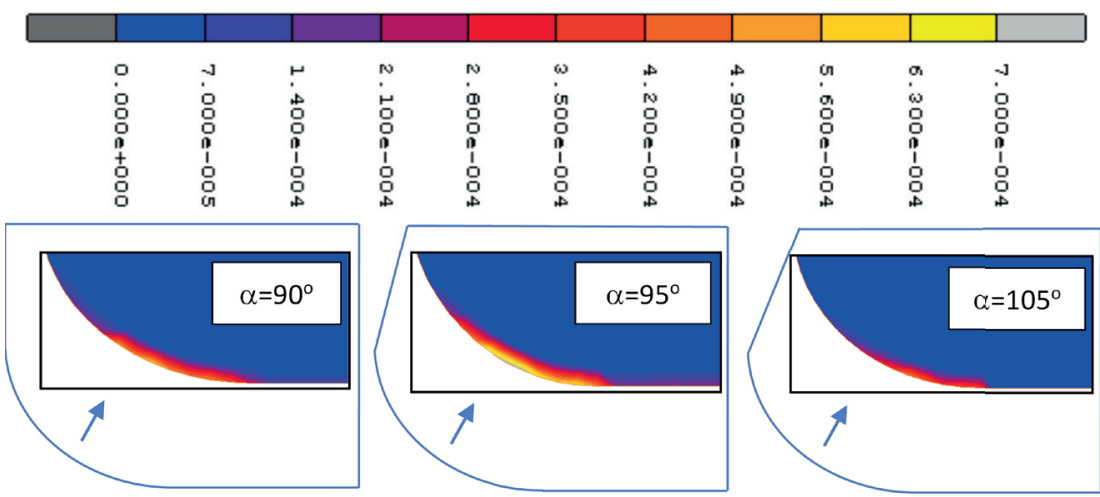

Fig. 8. Distribution of $w$, mm values in dies for the case: $\alpha=90^{\circ}, \alpha=95^{\circ}, \alpha=105^{\circ}, D_{o}=20.78 \mathrm{~mm}$ 
is where the wear is accumulated and reaches its greatest value. It should be noted that the greatest wear values are achieved by the dies depending on the angle of the working cone. For a flat die ( $\alpha$ $=90^{\circ}$ ), the maximum wear value was recorded at the 11th measuring point, while for a convex die $\left(\alpha=105^{\circ}\right)$ at the 13 th measurement point. It follows that the earliest maximum wear is in the case of a die with a $90^{\circ}$ cone angle, which is the result of a greater surface load on this die in this area compared to the others. In the case of the variant where different die diameters are considered at the same cone angle $\left(\alpha=90^{\circ}\right)$, the wear analysis

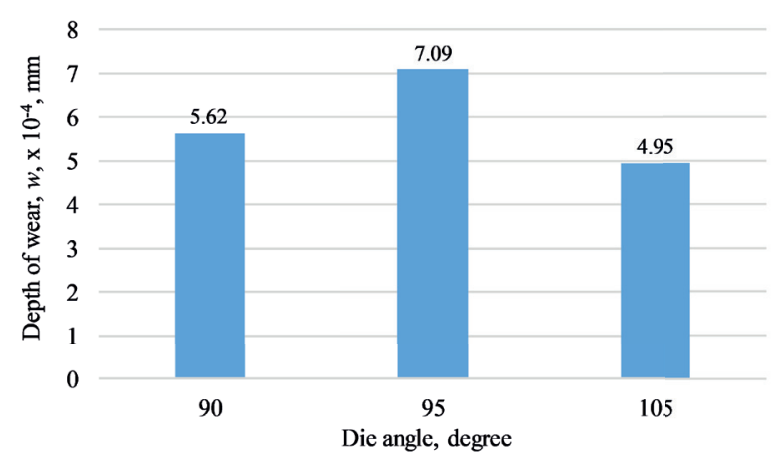

Fig. 9. Maximum calculated values of the wear depth for individual dies in critical areas
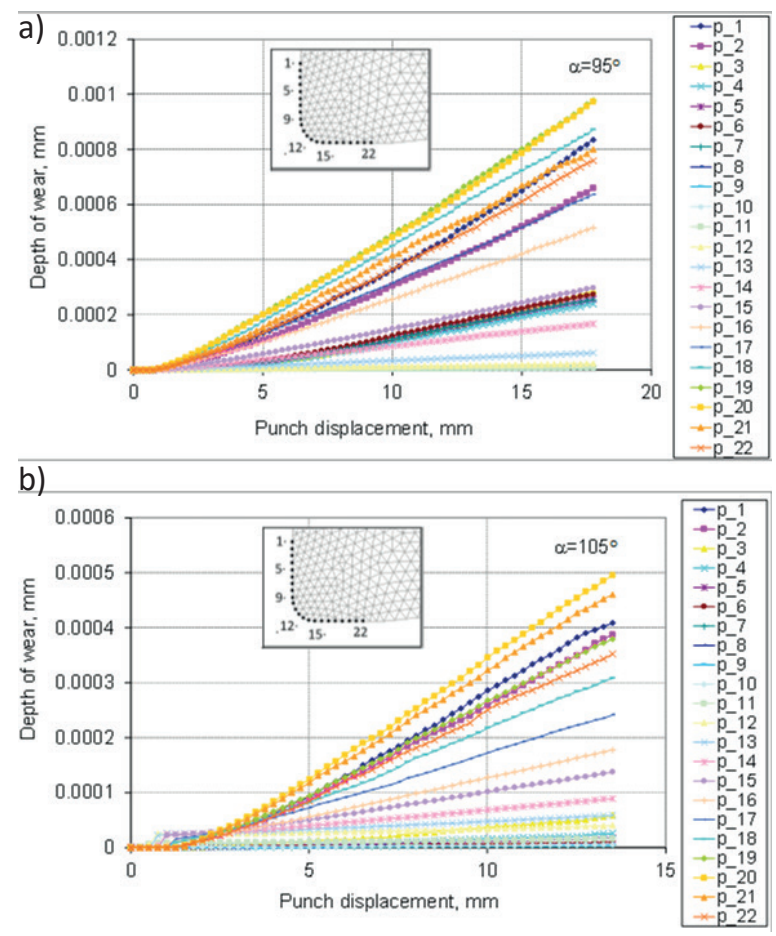

Fig. 10. Dependence of the depth of wear at individual measuring points on the displacement of the punch for die angle: a) $\alpha=95^{\circ}$, b) $\alpha=105^{\circ}$ was carried out in the area of the die corner radius, because the wear is greatest there (Fig. 12).

The distributions and values of the wear depth presented show that the largest wear depth occurs in the middle part of the die corner radius and for extrusion with $D_{o}=10.85 \mathrm{~mm}$ (Fig. 12a) which is almost 4.5 times greater than for $D_{O}=20.78 \mathrm{~mm}$ (Fig. 12b). Figure 14 shows the dependence of the depth of wear on the displacement of the punch for die with diameter. There are significant differences in the amounts of wear depending on the adopted diameter of the die $D_{0}$. Figure 13 shows the increase in the depth of wear on the displacement of the punch for dies with different diameters $D_{O}$. In the drawing process, in order to identify the size and places of wear on the numerical model, the area of the die length from $8 \mathrm{~mm}$ to $13 \mathrm{~mm}$ was analyzed (Fig. 14) in successive nodes separated by $0.05 \mathrm{~mm}$.

After testing the drawing process, it was observed that the most loaded area with the use of a conical die was the one near the calibrating part of the tool (Fig. 15). This heavy load observed in such a small area can be a source of rapid tool wear. In addition, there is a large gradient in the magnitude of the stress intensity at the point of

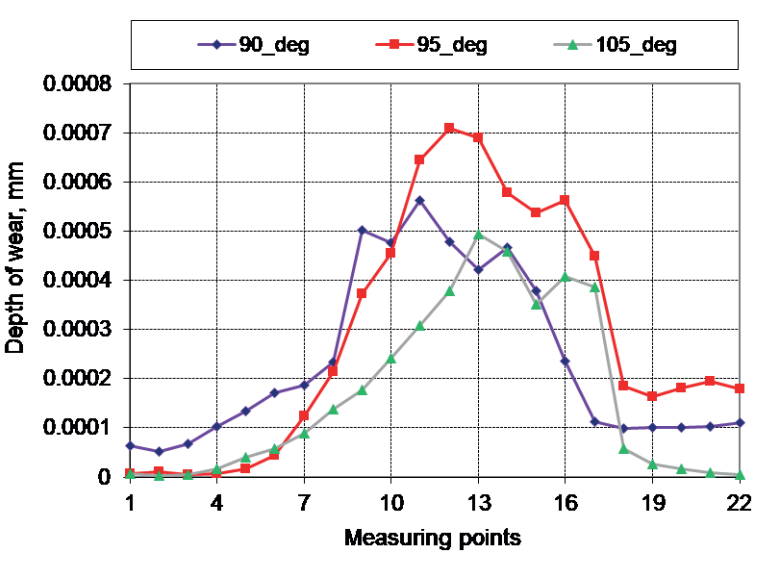

Fig. 11. Depth of wear in the tested places of dies

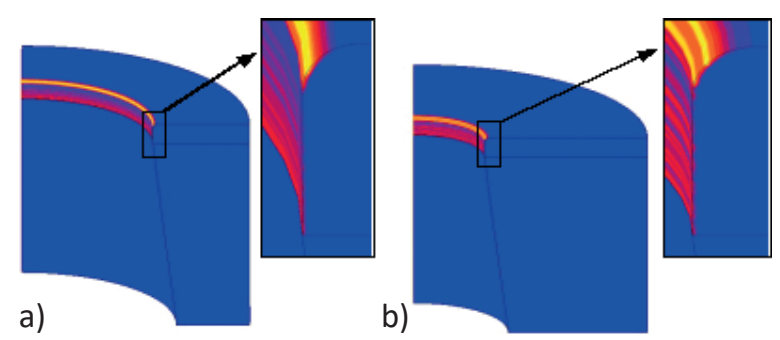

Fig. 12. Die areas with the highest wear intensity for the case: a) $\alpha=90^{\circ}, D_{o}=20.78 \mathrm{~mm}$, b) $\alpha=90^{\circ}, D_{o}=10.85 \mathrm{~mm}$ 
transition of the crushing cone to the calibrating part, which may also cause micro-cracks. In the case of the analysis of the stress distribution in the process of drawing the wire by the curved die (Fig. 15b), the stresses are distributed over a larger area of the working part of the tool without creating dangerous clusters. Such stress distribution seems to be more favorable from the point of view of the quality of the products obtained with the use of this process. This is justified in the industrial practices where such tools are often used to pull profiles of small diameters, and create appropriate conditions to obtain small products of good-quality. Moreover, such a favorable stress distribution significantly extends the life of the tools, reduces the costs resulting from, for example, by the need to regenerate them. Figure 16 shows the calculated depth of wear in the w measuring zone for the conical and curved dies.

After the drawing process was carried out by the tested dies, two areas with increased wear

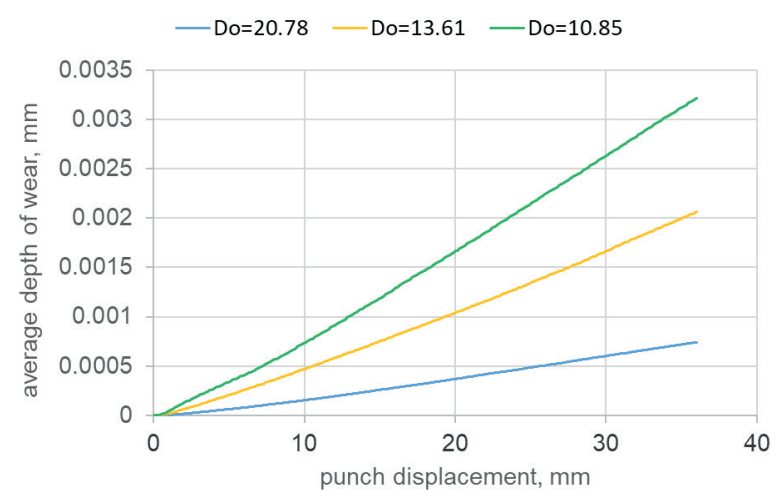

Fig. 13. Dependence of the depth of wear on the displacement of the punch for dies with different diameters

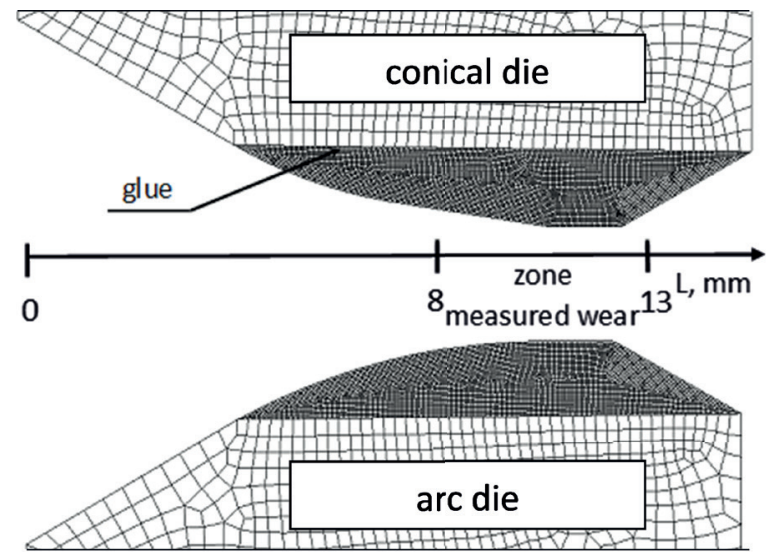

Fig. 14. The wear measurement area of the tested dies values were observed. When using a curved die, the first area of intense wear begins earlier compared to the cone. When analyzing the wear value of the tested dies, the second area of increased wear was observed at the same measuring length, while the recorded depth of the die wear $w$ for the conical drawing die is 2.3 times greater than for the curved die and amounts to $15 \mu \mathrm{m}$. The calculated depths of wear indicate that the "arcuate" geometry of the drawing die promotes lower and more even wear compared to the conical drawing die.

\section{CONCLUSIONS}

Abrasive wear is the most common type of wear in plastic forming processes. It results from the friction between the working surface of the tool and the extruded or drawn material. In order

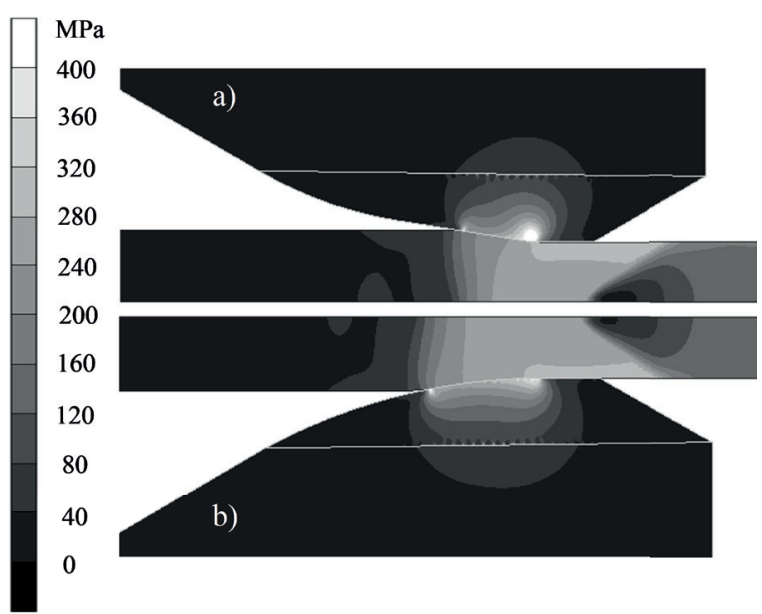

Fig. 15. Stress intensity distribution in the drawing process by conical and arc dies

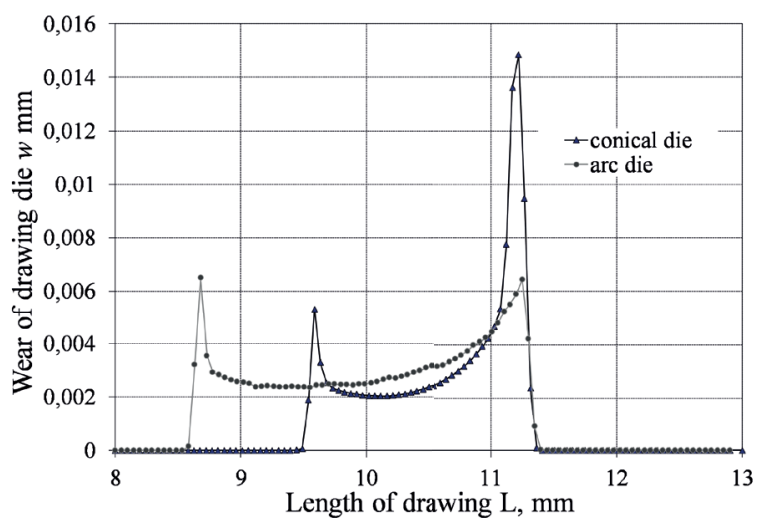

Fig. 16. The amount of wear along the length for the conical die and arc die 
to determine the amount of die wear, the adhesive Archard wear model was applied. It was implemented into the FEM-based program. As a result of the research, the areas on the surface of the tool particularly exposed to significant wear were determined, depending on its geometry. The analysis of the extrusion process showed that the highest wear of the die with a working cone angle equaled $95^{\circ}$. The greatest depth of the wear occurs in the central part of the die corner radius and for extrusion with $D_{o}=10.85 \mathrm{~mm}$ it is almost 4.5 times greater than for $D_{O}=20.78 \mathrm{~mm}$.

Considering both drawing dies, the greatest wear occurred at the point of the first contact of the wire with the tool and at the transition of the crushing zone to the calibrating one. In the case of the arc drawing die, the depth of wear in both places is similar and oscillates around the value of 6 micrometers. However, in the case of the conical die, the wear depth at the point of the first contact of the wire with the tool was similar and amounted to approximately 5 micrometers. On the other hand, at the point where the crumple zone passed in the calibrating part, it was three times larger and amounted to about 15 micrometers.

\section{REFERENCES}

1. Fu M.W., Yong M.S., Muramatsu T. Die fatigue life design and assessment via CAE simulation. International Journal of Advanced Manufacturing Technology, 2008, 35, 843-851.

2. Stahlberg U. J, Hallstrom A. Comparison between two wear models. Journal of Materials Processing Technology, 1999, 87(1-3), 223-229.

3. Altan T., Knoerr M. Application of the 2D finite element method to simulation of cold-forging processes. Journal of Materials Processing Technology, 1992, 35(3-4), 275-302.

4. Bramley A.N., Lord J.D., Beeley P.R., Davies B., J. Determination of wear resistance of hot work die materials. Annals of CIRP, 1989, 38(1), 231-234.

5. Lee GA, Im YT. Finite-element investigation of the wear and elastic deformation of dies in metal forming. Journal of Materials Processing Technology, 1999, 89-90, 123-127.

6. Kang J.H., Park I.W., Jae J.S., Kang S.S. A study on a die wear model considering thermal softening (I), construction of the wear mode. Journal of Materials Processing Technology, 1996, 96, 53-58.

7. Kang J.H., Park, I.W., Jae J.S., Kang S.S. A study on a die wear model considering thermal softening (II), application of the suggested wear mod- el. Journal of Materials Processing Technology, 1999, 94, 183-188.

8. Kragelsky, I.V., Dobychin M.N., Mombalov V.S. Friction and Wear Calculation Methods. Pergamon Press. New York, 1982.

9. Lee R.S., Jou J.L. Application of numerical simulation for wear analysis of warm forging die. Journal of Materials Processing Technology, 2003, 140(1-3), 43-48.

10. Lepadatu D., Hambli R., Kobi A., Barreau A. Statistical investigation of die wear in metal International Journal of Advanced Manufacturing Technology, 2006, 28(3), 272-278.

11. Painter B., Shivpuri R., Altan T. Prediction of die wear during hot-extrusion of engine valves, Journal of Materials Processing Technology, 1996, 59, 132-143.

12. Sińczak J., Łukaszek - Sołek A., Bednarek S. Ocena trwałości narzędzi w procesie wyciskania elementów cięgłowych i zderzakowych na przykładzie zderzaka kolejowego. Mechanik, 2008,8-9,694-699.

13. Sobis T., Engel U., Geiger M. A theoretical study on wear simulation in metal forming processes. Journal of Materials Processing Technology, 1992, 34, 233-240.

14. Hild R., Bergs T., Mattfeld P., Trauth D., Klocke F., Hoffmann D.C., Kruppe N.C., Brögelmann T., Bobzin K. Analysis of wear phenomena during forward extrusion under dry friction conditions. Wear, 2019, 426-427, 1362-1370.

15. Zhang, C. An Investigation of die wear behavior during aluminum alloy 7075 tube extrusion. Journal of Tribology, 2012, 135(1), 11602-11602.

16. Björk, T., Westergård R., Hogmark S. Wear of surface treated dies for aluminium extrusion - a case study. Wear, 2001, 249(3-4), 316-323.

17. Szota P., Mróz S., Stefanik A. Numeryczne modelowanie zużycia ciągadeł podczas ciągnienia drutu okrągłego. Hutnik-Wiadomości Hutnicze, 2001, 1, 138-141.

18. Nowotyńska I., Kut S. Prognozowanie wielkości zużycia ciągadła w zależności od przeciwciągu podczas ciągnienia drutu okrągłego w ujęciu MES. Hutnik-Wiadomości Hutnicze, 2012, 7, 488-492.

19. Wistreich J.G. The fundamentals of wire drawing. International Materials Reviews, 1958, 3(10), 97-141.

20.Shatynski S.R, Wright R.N. Die wear during wire drawing operations. Wire Technologies, 1979, 7, 59-62.

21. Kim T.H, Kim B.M., Choi J.C. Prediction of die wear in the wire-drawing process, Journal of Materials Processing Technology, 1997, 65, 11-17.

22. Pirso J., Letunovits S., Viljus M. Friction and wear behavior of cemented carbides. Wear, 2004, 257(34), 257-265. 
23. Lee K-H., Lee S-K., Kim B-M. Advanced simulation of die wear caused by wire vibrations during wire-drawing process. Transactions of Nonferrous Metals Society of China, 2012, 22(7), 1723-1731.

24. Hollinger S., Depraetere E., Giroux O. Wear mechanism of tungsten carbide dies during wet drawing of steel tire cords. Wear, 2003, 255(7-12), 1291-1299.

25. Lee S.K, Ko D.C, Kim B.M. Pass schedule of wire drawing process to prevent delamination for high strength steel cord wire. Mater \& Design, 2009, 30(8), 2919-2927.

26. Deng JX., Yang XF., Wang JH. Wear mechanisms of $\mathrm{A} 12 \mathrm{O} 3 / \mathrm{Tic} / \mathrm{Mo} / \mathrm{Ni}$ ceramic wire-drawing dies. Materials Science and Engineering A, 2006, 424(1-2), 347-354.

27. Lancaster J.K. The influence of substrate hardness on the formation and endurance of molybdenum disulphide films. Wear, 1967, 10(2), 103-117.

28. Łatka L., Szala M., Macek M., Branco R. Mechanical properties and sliding wear resistance of suspension plasma sprayed YSZ coatings. 2020, 14(4), 307-314.
29. Archard J.F. Contacts and rubbing of flat surfaces. Journal of Applied Physics, 1953, 24, 981-988.

30. Holm R. Electric contacts. Stockholm, Almqvist and Wiksells, 1946.

31. Gronostajski Z., Hawryluk M. The main aspects of precision forging. Archives of Civil and Mechanical Engineering, 2008, 8(2), 39-57.

32. Gillstrom P., Jarl M. Wear of die after drawing of pickled or reverse bent wire rod. Wear, 2007, 262, 858-867.

33. MSC Software, MSC. Marc Volume B, Element Library, Version 2014.

34. Łuksza J. Elementy ciągarstwa. Uczelniane Wydawnictwa Naukowo-Dydaktyczne. Kraków 2001.

35. https,//js-metals.pl/stopy-odlewnicze/10.02.2021

36. Sas-Boca I.M., Tintelecan M. Pop M., Dana M.P, Ilutiu-Varvara D-A, Mihu A.M. The Wire Drawing Process Simulation and the Optimization of Geometry Dies. Procedia Engineering, 2017, 181, 187-192. 